\title{
Recuento histórico de los desprendimientos de pintura mural en Teotihuacan
}

\author{
Montserrat Salinas Rodrigo
}

Introducción

I desprendimiento de pintura mural es una técnica de restauración que actualmente se recomienda sólo en casos extremos, pero resulta trascendente - conocer las razones y consecuencias del uso de este método en el pasado. Mediante la revisión bibliográfica de archivos y la entrevista a restauradores expertos en el tema, así como la observación directa de los murales desprendidos en la Zona Arqueológica de Teotihuacan, este ensayo busca conocer las causas y consecuencias de los métodos que se utilizaron en ese proceso, y explicar la presencia de numerosos fragmentos de su pintura en museos, acervos y colecciones.

Fue en dicho sitio donde se practicó la mayoría de los desprendimientos en México. Las técnicas más usadas para hacerlo fueron el stacco a massello, ${ }^{1}$ y el stacco, ${ }^{2}$ aunque existen, asimismo, algunos pocos ejemplos del strappo. ${ }^{3}$

Las técnicas de restauración utilizadas en México, incluidas las de desprendimiento, se instrumentaron, con adaptaciones a las necesidades locales, a partir de las desarrolladas en Italia. Dichas técnicas fueron producto del trabajo directo con las obras, con base en la bibliografía y enseñanza de expertos europeos que visitaron nuestro país, como Paolo y Laura Mora, o mexicanos que estudiaron en Europa, como Sergio Montero, Jaime Cama y Guillermo Sánchez Lemus.

Sin embargo, los criterios teóricos y el concepto de pintura mural han progresado y se han ido consolidando. Durante los años sesenta del siglo pasado, en Teotihuacan se desprendieron las pinturas de manera sistemática, ya que entonces los murales no se consideraban parte integral de un contexto arqueológico y arquitectónico, sino obras de arte móviles y museables.

En décadas más recientes estas nociones han cambiado y en la actualidad se considera que los valores más significativos de la pintura mural se aprecian únicamente en su contexto arquitectónico original, es decir, en aquel para el que fue creada ex profeso.

\footnotetext{
1 Stacco a massello significa en italiano "separación en bloque", y es el desprendimiento de la pintura mural con parte (o la totalidad) del soporte original de piedra o ladrillo (Brajer 2002:32).

2 Stacco, voz italiana, significa "separación"; con la técnica que lleva este nombre se remueve el enlucido y la capa pictórica.

3 Mediante el strappo, que significa "tirón" en italiano, sólo se remueve la capa pictórica, con algunos restos de enlucido en ciertos casos.
} 


\section{Causas generales del desprendimiento} de murales

Cualquier separación de la pintura mural de su soporte original constituye una alteración radical e irreversible para una y otro, ya que a partir de ella el muro queda desnudo, sin protección ni acabados, al mismo tiempo que la pintura sufre cambios visuales y materiales.

En consecuencia, el desprendimiento es una medida extrema, que sólo debe llevarse a cabo después del análisis profundo de cada caso, y cuando las causas de alteración de los murales no puedan controlarse ni eliminarse in situ.

Es posible identificar dos circunstancias que han orillado a los restauradores a realizar los desprendimientos. La primera, como única forma de salvar una pintura que, por distintas razones, esté en riesgo de destruirse, o bien como método de conservación emergente, cuando los inmuebles ya no pueden rescatarse, es decir:

- Si sufren deterioros estructurales irreversibles.

- Por el peligro de saqueo arqueológico o vandalismo.

- Como método único de salvación ante desastres inminentes, ya sean naturales, como inundaciones, incendios, erupciones volcánicas, o humanos, como conflictos armados o decisiones políticas.

- En el caso de la existencia de varias etapas constructivas sobrepuestas, se da la necesidad de retirar capas subyacentes para analizar los vestigios más antiguos.

La segunda circunstancia se refiere al mal estado en que se encuentran, debido al descuido de los murales. Se enumeran aquí los casos:

- El rechazo o aplazamiento de la conservación de los murales por los altos costos del tratamiento. Como la humedad es la principal causa de deterioro de la pintura mural, los remedios efectivos suelen comprender intervenciones radicales en las estructuras arquitectónicas.

- La carencia de condiciones en los sitios para asegurar la conservación de las pinturas.

- Insensibilidad e ignorancia frente al hecho de que las técnicas de desprendimiento, sobre todo el strappo, eventualmente provoquen alteraciones irreversibles.

- Cambios en el entendimiento de la pintura mural. Es el caso de la noción que se tenía cuando se hicieron los desprendimientos en Teotihuacan, diferente de la actual: entonces los murales se consideraban bienes muebles, obras que podían separarse de la arquitectura, mientras que hoy se conciben como parte integral de ésta.

\section{Consecuencias y alteraciones principales en las pinturas murales desprendidas}

El desprendimiento de pintura mural consiste en su separación, descontextualización y transferencia del muro para el que fue creada, a un nuevo soporte artificial y aislado: un "muro portátil" que le confiere la característica de movilidad de los bienes muebles. Es decir, se extrae un fragmento de una totalidad a la que en adelante se representa de manera aislada, transmitiendo un mensaje incompleto acerca de su origen.

Sergio Montero y otros especialistas en el tema afirman que cada mural está hecho para un sitio en específico y tiene una conexión única tanto con su espacio arquitectónico como con el observador localizado en un área determinada dentro de la totalidad de ese diseño, por lo que al sacarlo de dicho contexto, se pierde toda relación de conjunto (Salinas 2006:158).

El desprendimiento no sólo mutila la arquitectura y perturba las condiciones para la apreciación de las pinturas, sino que algunos métodos que se utilizan para realizarlo, como lo es el strappo, someten a las obras a un choque que altera gravemente la apariencia del trabajo pictórico (Mora 1984:245). La huella de la tela usada por esta técnica se marca en la capa de pintura, lo que provoca irregularidades físicas que ocasionan su detrimento estético. Más adelante se verán ejemplos de pintura teotihuacana que sufrieron este tipo de afectación.

Otras modificaciones tienen que ver con algunos de los procesos necesarios durante el desprendimiento y el montaje, ya que muchos son técnicamente irreversibles. Se trata de todos los procedimientos de conservación que implican la impregnación de adhesivos, fijativos y consolidantes sobre los materiales constitutivos de las obras, o aquellos que, para su montaje, eliminan los materiales constitutivos, como el adelgazamiento del repellado de las pinturas.

A modo de recapitulación, una pintura mural desprendida que ha sido consolidada con varias sustancias ajenas a su naturaleza, separada del paramento que revestía, que ha perdido irremediablemente una gran cantidad de materia original y que debe montarse en un nuevo soporte, se ve alterada en todos los aspectos, material, estética y funcionalmente. La transformación que sufre es muy drástica en todos los niveles y estos cambios pueden alterar tanto su apariencia original como su significado.

\section{Desprendimientos en Teotihuacan}

Las fuentes bibliográficas disponibles para la reconstrucción histórica de los desprendimientos en Teotihuacan son escasas; la mayor cantidad de información se encuentra en informes y documentos inéditos de los archivos de la Coordinación Nacional de Conservación del Patrimonio Cultural (CNCPC) del Instituto Nacional de Antropología e Historia (INAH) de ahí que una de las principales fuentes del presente trabajo haya sido la entrevista a expertos conservadores que trabajaron directamente en los desprendimientos y montajes de pinturas murales en Teotihuacan. Se revisaron, así, tanto los que se realizaron en el marco de las exploraciones arqueológicas como, ilegalmente, por saqueadores (muchas de las obras así sustraídas fueron vendidas a coleccionistas de arte prehispánico).

Entre los del primer tipo, es posible distinguir cuatro etapas fundamentales en las cuales se intervinieron las 
pinturas del sitio: primero, a finales del siglo xIX, con el arqueólogo Leopoldo Batres; la segunda, en los años cuarenta, estuvo a cargo del dibujante Agustín Villagra; la tercera corresponde al Proyecto de 1962 a 1965 dirigido por Ignacio Bernal, y la cuarta etapa, dentro del Proyecto Especial de Teotihuacan, de 1992 a 1994.

\section{Desprendimientos en el marco de la investigación arqueológica}

Primera etapa (1905): exploraciones del arqueólogo Leopoldo Batres

Las primeras exploraciones científicas en Teotihuacan se realizaron hacia 1846, y se concentraron en la excavación y reconstrucción de los edificios más impresionantes ubicados a lo largo de la Calzada de los Muertos. Estos proyectos iniciales fecharon sus materiales comparándolos con otros restos mesoamericanos conocidos en ese momento (Pasztory 1976:17).

En 1884, Leopoldo Batres inició formalmente las exploraciones en el sitio, y entre ese año y 1886 encontró en un grupo de montículos las pinturas del Templo de la Agricultura (Gamio 1979:106). Posteriormente, en 1905 emprendió su primera gran temporada de excavaciones en la antigua ciudad, la cual previó, por primera vez, la realización de arqueología a gran escala en monumentos mexicanos. Se exploró principalmente la Pirámide del Sol por sus cuatro lados, algunos edificios de la Plaza de la Luna y otros a lo largo de la Calzada de los Muertos, como el Templo de la Agricultura y parte de la Ciudadela (Bernal 1963:5-6).

Acerca de los primeros desprendimientos en el marco de la investigación arqueológica, contamos con datos que se remontan a esta etapa. Batres explica haber utilizado en 1894 un método que le permitió transportar murales mediante un cristal grueso, al cual adhirió con pegamento la capa en que estaban dibujadas las pinturas para desprenderlas del muro. Es probable que el mural específico al que se estaba refiriendo fuera el que desprendió del Templo de la Agricultura (Falcón 1988:225) -que hoy se exhibe en el Museo de Murales Teotihuacanos "Beatriz de la Fuente" $-y$, así, acaso éste sea el primer desprendimiento realizado en Teotihuacan y quizá en México.

Después de la intervención de Batres, prosiguieron las excavaciones de Manuel Gamio, en 1922, y otros, como Sigvald Linné, quien trabajó en la zona central de la ciudad entre los años 1934 y 1942. Además, otros arqueólogos excavaron los conjuntos habitacionales de Tetitla, Atetelco y Zacuala con gran abundancia de restos de pintura mural (Pasztory 1976:17).

Segunda etapa (década de 1940): intervención del dibujante Agustín Villagra

En el periodo comprendido entre 1942 y 1951, al trabajar los sitios de Tepantitla, Tetitla y Atetelco, se encontraron restos de murales in situ, así como gran cantidad de fragmentos separados de sus paramentos. El dibujante Agustín Villagra trabajó en su reconstrucción y copia (Villagra 1952:67-68, 70, 73), con lo que el suyo representa, sin duda, uno de los primeros intentos en México por conservar las pinturas murales en su contexto.

Aunque estas pinturas no fueron propiamente desprendidas, sino que se encontraron ya en pedazos, dentro del relleno o entre los escombros, este caso es importante, ya que numerosas secciones de pintura recuperadas entonces, aún hoy en día se encuentran almacenadas en condiciones precarias, en espera de su recontextualización. Dichas piezas se localizan en los conjuntos de Tetitla y Atetelco, en aposentos originales reconstruidos y habilitados como bodegas por Villagra, así como en el acervo de la Zona Arqueológica de Teotihuacan.

A la mayoría de estos fragmentos se les aplicó una capa de mortero de cemento sobre el repellado original, y algunos se encuentran en la fase intermedia entre el desprendimiento y el montaje, es decir, con la protección de velados, entelados y mortero de yeso necesarios para realizarlos.

Tercera etapa (1962 1965): Proyecto Teotihuacan del arqueólogo Ignacio Bernal

Aunque, como hemos visto, los desprendimientos de murales en Teotihuacan se realizaron desde las primeras exploraciones en la zona, no obstante aumentaron notablemente en los años sesenta. Los desprendimientos masivos tuvieron razones de carácter arqueológico, ya que se decidió retirar dichas pinturas para poder seguir explorando en subestructuras, es decir, se retiraron, junto con los murales, las etapas constructivas más recientes.

Por ejemplo, el restaurador Tomás Zurián reporta 10 desprendimientos realizados en agosto de 1963, argumentando que se tomó esta medida cuando los arqueólogos decidieron no reconstruir la arquitectura, lo que significaba que las pinturas murales quedarían expuestas a la lluvia, al calor directo, la humedad y a la eventual destrucción por parte de los visitantes (Zurián 1963).

Durante este periodo se desprendió y montó la mayoría de las pinturas murales que se encuentran hoy en los acervos y museos de la zona arqueológica. En estas labores participaron muchos restauradores, además de pintores de la Escuela de Artes Plásticas de la Esmeralda y algunos egresados de la Escuela de Restauración de Obras Artísticas de Bellas Artes, en las que se impartían clases a principios de los años setenta (Salinas 2006:177-178).

Durante dicho proyecto el grupo de restauradores fue liderado por Manuel Gaytán, restaurador autodidacto que tuvo como maestro a un conservador estadounidense. Había conjuntado un grupo de especialistas constituido por Arturo Solano, Alicia Islas, Antonio López Sáenz, Tomás Zurián, Rodolfo Rojas (Salinas 2006:179), Nora Moya, Beatriz Buberoff, Guillermina Dulce, Antonio Carvajal, Octavio Ochoa, Julián Rodríguez y José Marín, entre otros (Bernal 1963:9). 
El Centro Churubusco, o Departamento de Restauración, hoy Coordinación Nacional de Conservación del Patrimonio Cultural (CNCPC-INAH), no participó en los desprendimientos durante dicho periodo, pero se encargó, con la coordinación de Sergio Montero, de realizar el montaje de alrededor de 150 fragmentos de todos los tamaños (Salinas 2006:184).

En una entrevista, Montero expresó que fue un grupo de restauradores, que por razones políticas se separó del departamento, y de principiantes en la restauración o personas sin estudios, quienes llevaron a cabo numerosos desprendimientos sin experiencia previa. Para él, en términos técnicos se arrancaron las pinturas de los muros sin una metodología adecuada ni criterios de intervención definidos, por lo que se presentaron complicaciones de todo tipo y las pinturas sufrieron muchos daños (Salinas 2006:164).

En este periodo se desprendieron murales en diversas zonas de Teotihuacan, como el Templo de la Agricultura, el Palacio de los Jaguares, el Templo de los Caracoles Emplumados y del Quetzalpapálotl (zonas 2 y 3), los Animales Mitológicos en la zona 4, el mural de los Glifos en la zona 5A, además del Conjunto del Sol, La Ventilla, Zacuala, Atetelco y Yayahuala. ${ }^{4}$

Dentro de estos casos, resulta interesante el de las pinturas murales de Procesión de Aves Verdes, o los Pericos, que se hallan en la zona 2, en una de las subestructuras del Palacio de los Caracoles Emplumados, ubicado al noroeste de la Pirámide de la Luna. Justo debajo de los relieves de piedra que dan su nombre a este recinto, se localiza un basamento de cuatro caras construidas en talud-tablero. Actualmente se conservan tres de los tableros pintados.

Las pinturas de dos de las tres caras del templete fueron desprendidas mediante stacco a massello y una técnica parecida al strappo. Posteriormente se montaron en un soporte artificial de aluminio ${ }^{5}$ (Gaytán 1964:3-4) y se recolocaron in situ. Sin embargo, otra de las caras se conservó en su lugar, recibiendo los tratamientos usuales para la pintura mural, lo que permite comparar el estado de conservación de las pinturas sometidas a la transferencia con las que se dejaron en su contexto.

En los reportes de Manuel Gaytán en archivo, se registran los materiales y tratamientos que se llevaron a cabo sobre las pinturas entre mayo y agosto de 1964. Éstos fueron: el fijado con múltex al 20\% (acetato de polivinilo); el uso de un humectante nuevo, Ilamado "c. b.", para una prueba de desprendimiento con la técnica de strappo, develado con metil etil cetona; limpieza del adhesivo con

\footnotetext{
4 Para ubicar estas zonas, se recomienda consultar el plano en el libro de Arthur Miller (1973:40).

${ }^{5}$ Gaytán Ilama a las técnicas maccello y entonaco; describe esta última como una forma parecida al strappo, pero no sólo se desprende la capa pictórica, sino el intonaco y una pequeña parte de argamasa, lo que se llevaba a cabo golpeando la superficie, previamente velada con múltex, usando un martillo de hule.
}

agua caliente y bisturí; desincrustación de carbonatos; resane con resina epóxica sobre el soporte de lámina de aluminio, y reintegración de color. Cabe señalar que en ningún momento Gaytán justifica los tratamientos.

Las consecuencias de estos procedimientos se manifiestan hoy en las pinturas y se describen a continuación. Al comparar la superficie pictórica de las pinturas que se conservaron en su soporte original con la de las que fueron desprendidas y montadas en uno nuevo, es evidente que este tratamiento causó una transformación radical de todas las características visuales, como son: la saturación del color y de las tonalidades, el brillo y la textura (Figura 2).

En contraste, en la pintura mural que se conserva in situ podemos observar que su apariencia es muy nítida y los colores de la capa pictórica se revelan con alta saturación y brillo, así como gran homogeneidad, que le dan una textura satinada. Observamos también la huella de las herramientas, posiblemente pinceles, empleadas para la aplicación de la pintura (Figura 1).

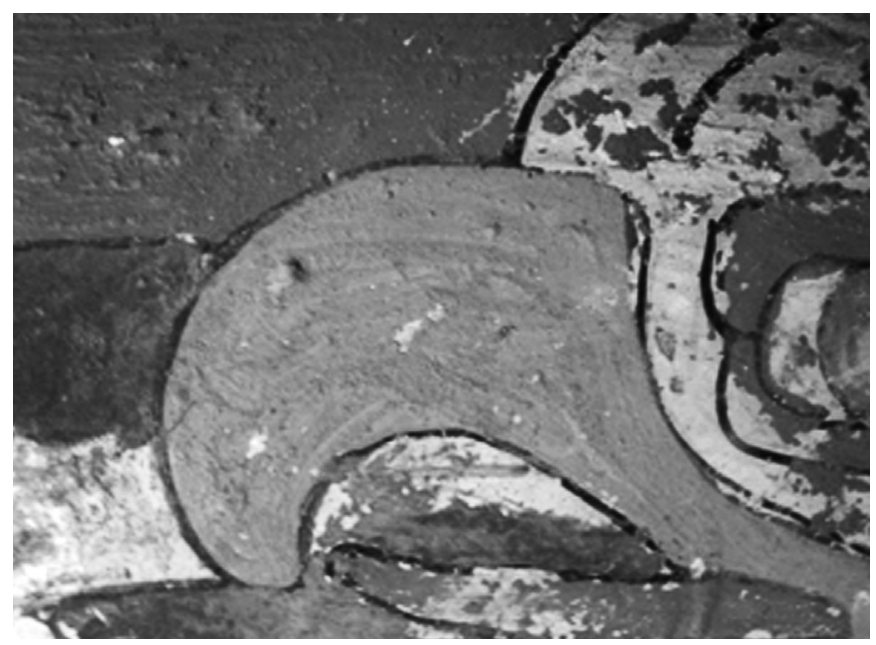

FIGURA 1. Pintura mural de los Pericos que no se desprendió. Se observa la textura original de la superficie. (Fotografía en cortesía de Montserrat Salinas).

Todas estas cualidades contrastan con la degradada apariencia de las pinturas desprendidas, cuya superficie se vio muy alterada por los velados y fijados con polímeros orgánicos, limpiezas profundas con solventes y repintes de la policromía. Estos daños se deben a un mal empleo de los materiales y a la deficiente realización del strappo, técnica que en este caso resultó especialmente destructiva (Figura 2).

Como otro ejemplo de dichas alteraciones, observamos en uno de los paneles tratados la impresión de la trama de los textiles que se usaron en el velado. Además, se aprecia que la superficie es muy brillante, ya que ésta fue completamente cubierta e impregnada por una película plástica (Figura 2).

Amén de los daños mencionados por su desprendimiento, el estado de conservación de los murales antes 


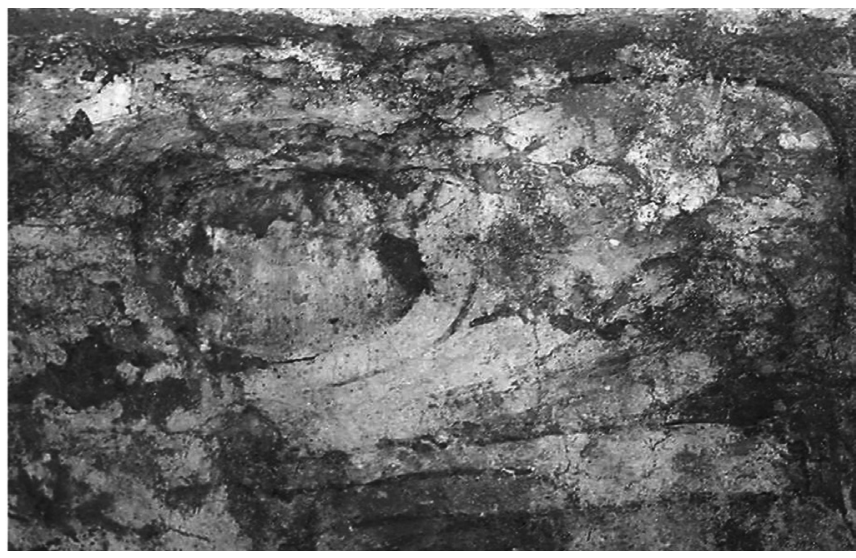

FIGURA 2. Uno de los murales que fue desprendido, donde se aprecia el oscurecimiento y cambios en la textura de la capa pictórica. (Fotografía en cortesía de Montserrat Salinas).

de ser intervenidos ya era, según Gaytán, deplorable. Describe que los aplanados se encontraban muy frágiles y quebradizos, presentaban separación de repellado en muchos puntos, grietas, y calcula que la decoración se había perdido en $25 \%$. Asimismo, se reporta que el develado fue muy lento, ya que las pinturas "no tenían aplanado, sino una lechada de cal" (Gaytán 1964:3-4).

Un aspecto positivo de esta intervención fue que las obras se recolocaron en su lugar original $y$, gracias a esta medida, no fueron totalmente descontextualizadas; por fortuna, hoy están estables en las condiciones ambientales circundantes.

Otro ejemplo notable de afectación de la capa pictórica es el Mural de los Animales Mitológicos. Aunque no podemos saber con certeza la técnica de desprendimiento que se utilizó con él, sí pueden observarse los mismos daños: oscurecimiento y deformación de la superficie pictórica, impresión de la trama de las telas de velados, fuertes repintes y montaje de lámina de aluminio. Otros de los casos poco afortunados son producto de montajes deficientes, como el del Mural de los Glifos, montado en lámina de aluminio y posteriormente dañado durante su manipulación (Langley 1993:136-137). En fragmentos de grandes dimensiones, como este caso, si el soporte no tiene suficiente fortaleza estructural, el aluminio, al ser excesivamente flexible, tiende a deformarse, provocando que el enlucido se separe de la lámina, se desfase $y$ fracture.

Como no se han localizado referencias escritas al respecto, al parecer fueron pocos los desprendimientos realizados en Teotihuacan durante las décadas de 1970 y 1980. Uno de los pocos murales que se sabe que fue desprendido en esta época es una pintura que representa a un Tlaloc negro, desprendida por Armando Soto en la década de 1980 (Salinas 2006:48), cuyo trabajo sobre los fragmentos se centró principalmente en la experimentación de nuevos materiales para soportes, y la realización de montajes para la gran cantidad de murales que se desprendieron en los años anteriores.
Cuarta etapa (1992-1994): Proyecto especial, arqueólogo Eduardo Matos Moctezuma

El 12 de octubre de 1992, el entonces presidente de la República, Carlos Salinas de Gortari, anunció un amplio programa de apoyo para la realización de 14 proyectos especiales de arqueología, entre los cuales tuvo lugar el Proyecto Especial Teotihuacan 1992-1994, dirigido por Eduardo Matos Moctezuma. Durante estos trabajos se dio mantenimiento a las áreas excavadas con anterioridad, con atención especial a la Calzada de los Muertos, las pirámides del Sol y la Luna, y al conjunto de Tetitla. Se realizaron excavaciones en la Pirámide del Sol, el Templo de Quetzalcoatl, La Ventilla y la Plaza de la Luna (Matos 1994:75-79). Se construyó el mirador y gradería frente al Templo de Quetzalcoatl, se creó el Centro de Estudios Teotihuacanos y se edificó un nuevo museo de sitio. Asimismo, se trató de reubicar a los comerciantes, con la creación de tres nuevos accesos a la zona.

Las restauradoras del proyecto, Catalina Figueroa y Zinna Rudmann, extrajeron de La Ventilla, mediante el proceso de stacco a massello, un mural en dos partes y un altar. Este trabajo se llevó a cabo en conjunto con la Dirección de Restauración -hoy Coordinación Nacional de Conservación- del Patrimonio Cultural (Figura 3).

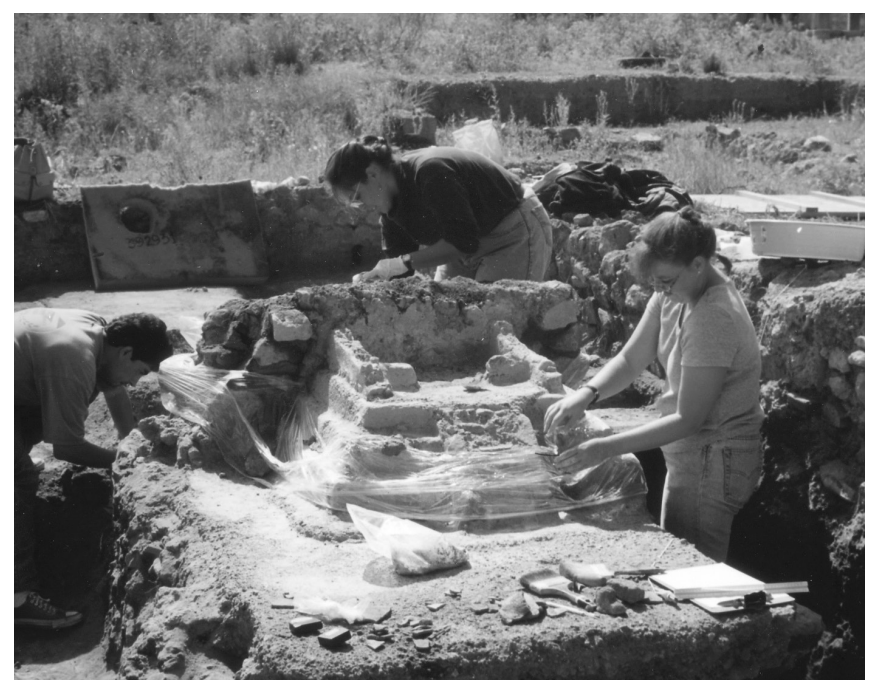

FIGURA 3. Preparación para el desprendimiento de altar en La Ventilla. (Fotografía de Catalina Figueroa, cortesía: CNCPC-INAH).

Las dos piezas de pintura desprendidas fueron llevadas al acervo de la zona arqueológica, donde permanecen aun hasta hoy (Figueroa 1994). El caso del altar es más afortunado, ya que se montó adecuadamente, y se exhibe en el Museo de Murales Teotihuacanos (Figura 4).

Del mismo barrio de La Ventilla también se extrajo un conjunto de 63 fragmentos de pintura sobre una fina capa de barro crudo, reutilizados por los teotihuacanos como parte del relleno que cubría la Plaza de los Chalchihuites. Los fragmentos nunca recibieron tratamiento, muy probablemente debido a cuestiones administrativas (Figueroa 1994). 


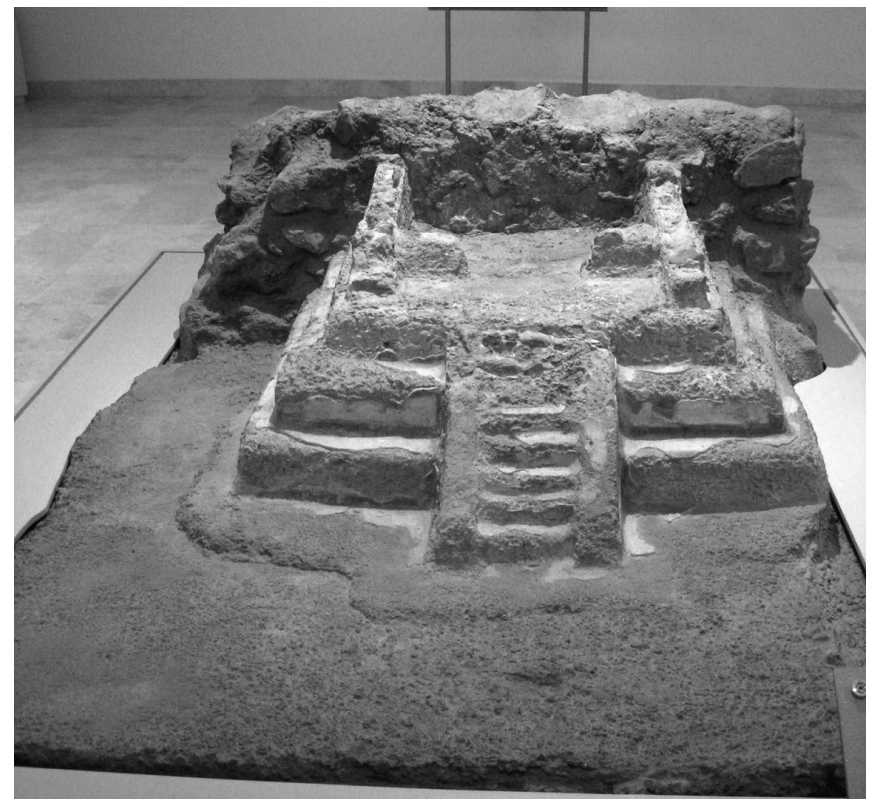

FIGURA 4. Altar que se exhibe en el Museo de Murales Teotihuacanos "Beatriz de la Fuente". (Fotografía en cortesía de Montserrat Salinas).

\section{Desprendimientos ilegales}

Son bien conocidas varias colecciones de fragmentos de murales adquiridos $y$, en algunos casos, exportados en épocas en las que no se contaba con las herramientas legales que previenen la adquisición y exportación de bienes arqueológicos. A continuación se dan algunos ejemplos:

Entre 1963 y 1968, el arquitecto Harald J. Wagner, aficionado al arte precolombino, que residió en México, adquirió importantes segmentos de pintura teotihuacana. Se desconoce la forma precisa en que fueron extraídos tanto del sitio como del país.

Como dichas pinturas fueron vistas en San Francisco por algunas personas -incluidos curadores locales- desde finales de los años sesenta, se deduce que fueron sustraídas del país antes de esa década (Bone 1986:2).

Es posible que los murales hubiesen sido descubiertos accidentalmente por los usuarios de las tierras, al construir cimientos, o durante la siembra, del mismo modo en que, a principios de los años cuarenta, se hallaron los murales de Tepantitla, Tetitla y Atetelco (Berrin 1988:29).

Seguramente, los fragmentos se desprendieron sin capacitación técnica alguna, y fueron seleccionados por los saqueadores según el estado de conservación de la superficie y la facilidad técnica para su remoción. El área por cortar se dividió en secciones, y posiblemente comenzaron la operación introduciendo un cincel en el aplanado, por la parte superior del muro, para ir cortando alrededor de la sección que les interesaba, fracturando y destruyendo grandes extensiones de pintura. Además del deterioro de las pinturas, uno de los daños más graves fue la eliminación de su relación con el contexto arqueológico, lo que hace que en muchos casos se ignore la ubica- ción exacta de dichos murales (Montero 1987 y Berrin 1988:30).

Según Alicia Islas, restauradora que participó en los desprendimientos oficiales durante el periodo 19621965, el robo de los murales se dio de manera paulatina; la adquisición de la colección Wagner tuvo lugar durante los mismos años en que ellos trabajaron en el sitio. Los saqueadores debieron ir sacando las pinturas de una en una, o en conjuntos pequeños (Salinas 2006:170-179).

Podemos suponer la procedencia de algunas pinturas gracias a René y Clara Millon, quienes descubrieron restos de pintura muy similar a la que fue saqueada en una estructura a 600 m de la Plaza de la Luna, en el área que han Ilamado el Barrio de las Pinturas Saqueadas, o Techinantitla (Millon 1991:185).

En febrero de 1986 fueron devueltos a nuestro país 55 fragmentos de la colección Wagner, que representan $75 \%$ del total del conjunto que se encontraba en el Museo $\mathrm{M}$. H. de Young Memorial (Montero 1987), algunos de los cuales ahora se exhiben en el Museo Nacional de Antropología de la Ciudad de México. Varios fragmentos más quedaron distribuidos entre las ciudades de San Francisco y Seattle (Montero 1987:168).

Otras pinturas se encuentran en la Universidad de Harvard, en Washington, D. C. (colección Bliss), como es el caso de una de las escenas del Jaguar Arrodillado, procedente del palacio de Tetitla (Coggins 1996:39). Esta pintura se sustrajo de su sitio original en los años treinta (Sejourné 1959:65). Diego Rivera recordaba que le fue ofrecida en venta, pero en ese momento no había podido comprarla y que años después, en 1940, la vio en Los Ángeles, en la galería de Stendhal, que era un comerciante de arte; posteriormente fue adquirida por Robert Woods Bliss, millonario y senador estadounidense. El pintor relata cómo funcionarios mexicanos intentaron persuadir al senador de que devolviera el mural a México. No obstante, Bliss prefirió dejarlo en préstamo a la National Gallery de Washington (Cardona 2007:88-90), y, en 1960, terminó por donar su colección a Dumbarton Oaks, Harvard (Benson 1993:15-32).

Por otro lado, Kathleen Berrin ha rastreado la presencia de veinte fragmentos más en los Estados Unidos, ocho en Europa y uno en Israel (Berrin 1988:40). Nueve museos estadounidenses y un instituto de bellas artes aceptaron donaciones de fragmentos de particulares entre 1967 y 1979 , algunos de los cuales fueron repatriados, como es el caso de las piezas de Berkeley, California ${ }^{6}$ (Berrin 1988:31).

\footnotetext{
${ }^{6}$ Estas instituciones son: Ios museos Americano de Historia Natural y el de Arte St. Louis, de Nueva York; el Chrysler, en Norfolk, Virginia; los museos de Historia Natural de Denver, y el del Condado de Los Ángeles; el Museo de Arte Kimbell, Forth Worth, Texas; el Museo Público de Milwaukee; el de Arte y Arqueología de la Universidad de Missouri, Columbia, y el de Antropología Robert H. Lowie, de la Universidad de California, Berkeley, así como el Instituto de Bellas Artes de la Universidad de Nueva York.
} 
Entre los museos estadounidenses que cuentan con murales teotihuacanos están el de Arte de Cleveland y el Kimbell de Arte, de Forth Worth, Texas. Los fragmentos en ellos pertenecen a una serie de pinturas que fueron extraídas de Amanalco. Otros más se encuentran en Holanda, en el Rijks Museum Voor Volkerkunde, en Leiden (De la Fuente 1995b: vol. I, 445).

En México, el Museo Anahuacalli, conformado por la colección de arte prehispánico de Diego Rivera, cuenta con fragmentos de murales teotihuacanos que probablemente proceden de Tetitla. Cabe recordar que en esa época no existía legislación que regulara el acopio de obras precolombinas, por lo que su comercialización era legal. El pintor expresó sus intenciones de reunir las piezas para evitar que salieran del país, y de ubicarlas en un recinto accesible para la gente (Coronel 2007:26-27).

El pintor Rufino Tamayo consiguió fragmentos que posiblemente proceden de Tlacuilapaxco y que hoy se encuentran en el museo de arte de la ciudad de Oaxaca que Ileva su nombre (Coronel 2007:26-27).

Otro importante conjunto de pinturas que proceden de Techinantitla forma parte del acervo de arte prehispánico de Josué y Jacqueline Sáenz, quienes reunieron piezas que hoy custodia la Fundación Amparo (Del Villar 1996:40; García Moll 1995:435-439). Además, el Instituto Mexiquense de Cultura, en Toluca, alberga aproximadamente 10 pinturas de Zacuala, Techinantitla y el Conjunto del Sol (De la Fuente 1995c: vol. I, 441).

Otro ejemplo de repatriación es el de las obras que pertenecieron a la colección formada por Allen y Carmen Christensen, quienes además, en 1957, crearon la fundación que por nombre lleva su apellido. Mientras se exhibía en la Universidad La Trobe, en Melbourne, Australia, el rector de la institución informó a la embajada mexicana de la existencia del conjunto de murales, que fue devuelto a México en 1994 (Solís 1996:69-70; The Christensen Fund 2003).

\section{Conclusión}

Para nosotros resulta claro que el desarrollo técnico e histórico del proceso de desprendimiento de pinturas murales y la evolución de los montajes en México están ligados de manera directa y específica a la historia de Teotihuacan; el que quizás es el primer desprendimiento en nuestro país se hizo en este sitio arqueológico. Además, contamos con ejemplos de que allí se han practicado todas las técnicas conocidas para este procedimiento, y los fragmentos que resultaron de él fueron objeto de experimentación con varios tipos de soportes, incluidos los de lámina de aluminio, no utilizado en ningún otro sitio.

A pesar de ello, dichos desprendimientos se hicieron de manera intuitiva, en el intento de resolver problemas prácticos o de cubrir las necesidades que iban surgiendo en las exploraciones arqueológicas, así como en la subsecuente intervención de las pinturas teotihuacanas.
Un factor importante en la toma de decisiones respecto de los desprendimientos fue la ignorancia y la indiferencia ante las consecuencias (daños) que eventualmente entraña el empleo de esta técnica, lo que contribuyó a la gran cantidad de ellos que se realizaron en los años sesenta.

En muchos casos, los despredimientos también respondieron a las exigencias de la investigación arqueológica de ese momento. El equilibrio entre los intereses de la restauración y los de la arqueología es aún hoy difícil de lograr, pero es indispensable encontrar un punto de acuerdo para el éxito de toda la conservación arqueológica, y propiciarlo es responsabilidad de todos los involucrados.

Las consecuencias de la técnica del strappo se ejemplifican a través de los Murales de los Pericos, en donde la comparación entre las pinturas que no fueron sometidas a este proceso y las desprendidas ilustra con claridad las alteraciones irreversibles, tanto materiales como estéticas, que pueden causar los desprendimientos hechos con poco conocimiento y experiencia. Como se ha dicho, en la época en que éstos se hicieron los murales no se consideraban parte integral de la arquitectura, sino bienes muebles u objetos transportables. La progresiva conceptualización de la pintura mural como parte integral de la arquitectura se refleja en la notable disminución de la práctica de los desprendimientos después de la década de 1960.

Otros muchos murales fueron separados de sus contextos ilegalmente, como consecuencia de un momento en que no se contaba con las herramientas legales para prevenir el saqueo, el tráfico ilícito y la exportación de los bienes arqueológicos. Después de la promulgación de la Ley Federal Sobre Monumentos y Zonas Arqueológicos, Artísticos e Históricos, en 1972, estas problemáticas han disminuido significativamente, lo cual ha llevado a una reducción en el número de desprendimientos realizados.

Por ahora, es imposible dar una estimación precisa sobre la cantidad de pinturas murales almacenadas en cada bodega del sitio arqueológico de Teotihuacan, así como del estado de conservación real en que se encuentran. Sin embargo, para salvaguardar los numerosos fragmentos que se tienen, es urgente el diseño e instrumentación de estrategias de gestión que incluyan un diagnóstico general de las pinturas desprendidas, su catalogación, conservación y restauración, con el objetivo de devolverles, en la medida de lo posible, la coherencia que han perdido al ser separados de su contexto arqueológico y arquitectónico.

La historia de la conservación arqueológica en México está aún por escribirse. Los detalles de la evolución de los procesos técnicos, de la lógica de la toma de decisiones que llevaron a ciertos tratamientos y sus consecuencias son elementos sustanciales para comprender nuestro desarrollo profesional. Sirva esta investigación sobre el desarrollo del desprendimiento de las pinturas murales de Teotihuacan como una invitación a los necesarios 
diálogos y reflexiones sobre nuestro devenir profesional y a realizarlos de una manera sistemática, crítica y respetuosa. Así podrá desprenderse una visión clara sobre la gran responsabilidad que implica el trabajo del restaurador en el presente y futuro del legado patrimonial prehispánico de nuestro país.

\section{Referencias}

Benson, Elizabeth P.

1993 "The Robert Woods Bliss Collection of Pre-Columbian Art: A Memoir" en Elizabeth Hill Boone (ed.), Collecting the Pre-Columbian Past, Washington, Dumbarton Oaks Research Library and Collection-Trustees for Harvard University: 15-32. Bernal, Ignacio

1963 Teotihuacan, México, INAH.

Berrin, Kathleen

1988 "Reconstructing Crumbling Walls: A Curator's History of the Wagner Murals Collection", en Kathleen Berrin, (comp.), Feathered Serpents and Flowering Trees. Reconstructing the Murals of Teotihuacan, San Francisco, The Fine Arts Museum of San Francisco: 24-44.

Bone, Lesley

1986 Teotihuacan Mural Project, wAAC Newsletter, 3 (8), documento electrónico disponible en [http: I $\backslash$ palimsest.stanford.edu\waac], consultado en julio de 2007.

Brajer, Isabelle

2002 The Transfer of Wall Paintings. Based on Danish Experience, Londres, Archetype Publications Ltd.

Cardona, Peña, Alfredo

2007 "El negocio del arte prehispánico", en Diego Rivera: Coleccionista, México, Conaculta, INBA: 77-99.

Coronel, Juan Rafael

2007 "Diego Rivera: Idólatra", en: Diego Rivera: Coleccionista, México, Conaculta, INBA: 18-41.

Coggins, Clemency Chase

1996 "Ética de la adquisición arqueológica", en Arqueología Mexicana. "Saqueo y destrucción, un futuro sin pasado", 21 (IV): 34-39.

Falcón Álvarez, Tatiana 1988 "La conservación, futuro de la pintura mural", en Teresa Uriarte (coord.), Fragmentos del pasado. Murales prehispánicos, México, INAH/ IIE-UNAM: 222-239.

Figueroa, Catalina y Zinna Rudman

1994 Carta a Matos Moctezuma, 1994. Proyecto Especial Teotihuacan 1992-1994, México, INAH, Archivo Técnico de la CNCPC, Expediente de la Zona Arqueológica de Teotihuacan, Estado de México, Legajo 5, 1990-2000.

Fuente, Beatriz de la, et al.

1995a "Colección Museo Diego Rivera Anahuacalli", en Beatriz de la Fuente (coord.), La pintura mural prehispánica en México. Teotihuacan, México: IIE-Unam, I: 431-433.

1995b "Museo de Arte Prehispánico Rufino Tamayo en Oaxaca", en Beatriz de la Fuente (coord.), La pintura mural prehispánica en México. Teotihuacan, México, IIE/ UNAM, I: 445-446.
Fuente, Beatriz de la, et al.

1995c "Museo de Antropología del Instituto Mexiquense de Cultura, Toluca, Estado de México", en Beatriz de la Fuente (coord.), La pintura mural prehispánica en México. Teotihuacan, México, IIE-UNAM, I: 441-443.

Gamio, Manuel

1979 La población del Valle de Teotihuacan, México, INI:2.

García Moll, Roberto

1995 "Fundación Amparo /Museo Amparo", en Beatriz de la Fuente (coord.), La pintura mural prehispánica en México. Teotihuacan, México, IIE-UNAM, I: 435-439.

Gaytán, Manuel

1964 Vigésimo primer Informe mensual del 1 al 30 de junio de 1964, Proyecto Teotihuacan, Temporada V, Departamento de Restauración, México, INAH, Archivo Técnico de la CNCPC, junio de 1964, Expediente de la Zona Arqueológica de Teotihuacan, Estado de México, Legajo 1, 1963, 1964, 1965. Langley, James

1993 "Symbols, Signs and Writing Systems", en Kathleen Berrin y Esther Paztory (eds.), Teotihuacan. Art from the City of Gods, San Francisco, The Fine Arts Museums of San Francisco/ Thames and Hudson: 129-139.

Manzanilla, Linda

2001 "La zona del altiplano central en el Clásico", en Linda Manzanilla y Leonardo López Luján (coords.), Historia antigua de México, II, El horizonte Clásico, México, INAH/ UNAM/ Miguel Ángel Porrúa: 203-239.

Matos Moctezuma, Eduardo

1994 "Teotihuacan", Arqueología Mexicana, vol. II, núm. 10, octubre-noviembre: 75-79.

Miller, Arthur

1973 The Mural Paintings of Teotihuacan, Washington, Dumbarton Oaks Research Library and Collection, Trustees for Harvard University.

Millon, René

1988 "Where do they all come from? The Provenance of the Wagner Murals from Teotihuacan", en Kathleen Berrin (comp.), Feathered Serpents and Flowering Trees. Reconstructing the Murals of Teotihuacan, San Francisco, The Fine Arts Museums of San Francisco: 78-113.

1991 "Descubrimiento de la procedencia de las pinturas murales saqueadas con representaciones de personajes que Ilevan el Tocado de Borlas", en Rubén Cabrera (ed.), Teotihuacan 1980-1982. Nuevas Interpretaciones, México, INAH: 186-192.

Montero, Sergio

1987 "Guión para la restauración de las pinturas teotihuacanas de la colección Wagner", en Colección Wagner. Fragmentos de pintura mural teotihuacana, México, ENCRym/ INAH/ SEP, Seminario-Taller de Obra Mural, Centro de Documentación de la ЕлсRум.

Mora, Paolo, Laura Mora y Paul Philippot 1984 Conservation of Wall Paintings, Londres, Butterworths.

Pasztory, Esther

1976 The Murals of Tepantitla, Teotihuacan, Nueva York, Garland Publishing (Outstanding Dissertations in the Fine Arts). 
Ramírez, Gerardo

2003 "El Museo de la Pintura Mural Teotihuacana. La piel de la ciudad de los dioses", en Arqueología Mexicana. "Teotihuacan, ciudad de misterios", 64 (XII): 66-69.

Ruiz, Ma. Elena

1995 "Museo Nacional de Antropología, Cd. de México", en Beatriz de la Fuente (coord.), La pintura mural prehispánica, en México. Teotihuacan, México, IIE-UNAM, vol. I: 447-457.

Salinas, Montserrat

2006 "Desprendimiento y soportes para pintura mural. El caso de la pintura mural teotihuacana", tesis de Licenciatura en Restauración de Bienes Muebles, México: ENCRyM-INAH.

Séjourné, Laurette

1959 Un palacio en la ciudad de los dioses (Teotihuacan). Exploraciones de 1955-1958, México, INAH/ Talleres Helio.

Solís, Felipe

1996 "Grandes logros en la recuperación del pasado prehispánico", Arqueología Mexicana. "Saqueo y destrucción, un futuro sin pasado", 21 (IV): 68-73.

\section{Resumen}

El desprendimiento de pintura mural es una técnica de restauración que actualmente se recomienda solamente en casos extremos, ya que estas obras de arte se consideran parte integral de la arquitectura. El presente artículo documenta y analiza la historia de los desprendimientos de pintura mural en la Zona Arqueológica de Teotihuacan, México. Se examinan las diferentes circunstancias que llevaron a la decisión de desprender las pinturas. Con base en ello, se plantea la urgente necesidad de desarrollar soluciones de conservación y restauración para la enorme cantidad de fragmentos que, producto de este legado histórico de desprendimientos, se encuentran en bodegas y museos.

\section{Palabras clave}

Desprendimiento, pintura mural, Teotihuacan, conservación, Restauración.
The Christensen Fund

2003 About Christensen Fund, documento electrónico disponible en [www.christensenfund.org], consultada en marzo del 2003.

Villagra, Agustín

1952 "Teotihuacan, sus pinturas murales", Anales del Instituto Nacional de Antropología e Historia, 33 (V): 67-74.

Villar, Mónica del 1996 "El coleccionismo arqueológico mexicano. Otro punto de vista. Entrevista con Josué Sáenz", Arqueología Mexicana. "Saqueo y destrucción, un futuro sin pasado", 21 (IV): 40-47.

Zurián, Tomás

1963 Undécimo Informe mensual del 1 al 31 de agosto de 1963, Proyecto Teotihuacan, Temporada V, Departamento de Restauración, México, INAH, Archivo Técnico de la CNCPC, Expediente de la Zona Arqueológica de Teotihuacan, Estado de México, Legajo 1, 1963, 1964, 1965.

\section{Abstract}

Mural painting detachment is currently recommended only in extreme cases, due mainly to the fact that these works are considered an integral part of architecture. This paper reviews the use and consequences of detachment techniques at the archaeological site of Teotihuacan. It examines the circumstances that influenced the decisionmaking process of detaching a mural painting, in order to place an urgent demand for conserving and restoring the enormous number of Teotihuacan mural fragments produced by these detachments.

\section{Keywords}

Detachment, Wall painting, Teotihuacan, Conservation, Restoration. 